\title{
Relative Perceived Effectiveness of Training and Development Practices on the Organisational Performance - Case Analysis of the South African Broadcasting Association
}

\author{
Abhinanda Gautam and Devin Shutte
}

\begin{abstract}
There is currently a growing realisation in the business environment of the importance of people advantage for organsations' competitive advantage. Training plays an imperative role in improving and updating employee skills and competencies. In turn, this leads to value addition, thus increasing organisations' performance. This study aims to analyse the impact of training and development practices on the organisational performance of the South African Broadcasting Corporation (SABC). The study empirically tests the effect of training and development on financial performance with employee competence and learning interest acting as mediating mechanisms. The study also analyses the impact of employee training and development practices on individual, group, and organisational learning. The findings suggest that (1) the organisation needs to deliver consistent training and development initiatives relevant to the needs of employees and (2) focus on addressing identified skills, knowledge and abilities gaps to enhance its performance.
\end{abstract}

Index Terms-Training, development, individual, group, organization, learning, organisational performance.

\section{INTRODUCTION}

The resource-based theory is of the view that it is imperative for organisations to understand the emerging role of people advantage for competitive advantage in a dynamic business environment. The focus of this study is firstly on training effectiveness, which is a subdivision of human capital resourcing practices, and secondly on the relationship between training and organisational performance [1].

According to [2], the productivity and efficiency of any organisation largely depend on manpower competency. Training plays a major role in updating employee skills.

One method in which the potential workforce can be uplifted is through practical skills training. According to [3], a new economy drives companies to provide better services in line with Internet and electronic commerce. In South Africa, however, the creation of technological jobs is not suited for casual workers. This explains why individuals have to constantly reinvent the most critical issues facing managers in South Africa today. Globally, competitive export industries, as vital as they are for bringing South Africa into the new economy, will not create jobs in the numbers required. Training, skills development and job creation are therefore

Manuscript received August 24, 2016; revised December 10, 2016.

Abhinanda Gautam is with Regenesys Business School, Gauteng, South Africa (e-mail: abhinandag@regenesys.co.za). still high on the priority list of South African managers if the economy is to improve as a whole.

According to [4], the organisation operates in a dynamic environment, characterised by fast changing technological and broadcasting media platforms. The organisation's much-anticipated migration from analogue to digital television, the establishment of Internet as global media platform and the emergence of new technologies are some changes that are already happening in South Africa.

These changes pose serious transformational challenges from a human resources viewpoint. For instance, skills and talent profiles are required, as well as training and development. In addition, talent management strategies need to be adopted by the SABC, both now and in the future.

\section{Research Objectives:}

- To investigate factors affecting training and development of employees at the SABC.

- To determine the impact of training and development on organisational productivity at the SABC.

- To investigate the impact of training on employee performance at the SABC.

- To recommend strategies to improve the training and development of SABC employees.

\section{LITERATURE REVIEW}

Training refers to the acquisition of the skills, knowledge and competencies required to perform a task, by means of teaching. [5], defines training as "a planned effort to facilitate the learning of job-related knowledge, skills, and behavior by employees".

Training addresses gaps or discrepancies between an ideal and an optimal stage of development. However, if we distinguish between desired and actual work methods or between desired and actual results, it becomes clear that needs arise on the job [6].

One of the larger aspects of developing employees' skills and abilities is actual organisational focus on the employee to improve, either as a person or as a contributor to the organisation. The attention offered by an organisation, coupled with increased expectations following training opportunity, can lead to a self-fulfilling prophecy of enhanced output by the employee. Employees who receive regular, scheduled feedback such as training, along with an increase in expectations, actually have a higher level of worker [7].

According to [8], Most human resource professionals would agree that a significant aspect of employee 
development is limiting organisational liability when training employees. Certain jobs require training and certification in order for an employee to successfully execute the minimum job requirements for a position.

The SABC embarked on a process of up-skilling both its existing and new employees. A total training investment of approximately $\mathrm{R} 23 \mathrm{~m}$ (1,6\% of the compensation budget) allowed employees to participate in 4346 skills programmes and short courses in the broadcasting, information technology, and marketing and journalism fields.

The partnership between the MICT SETA, the National Skills Fund and the SABC contributed to job creation and entrepreneurship activities via internship and learnership programmes. A total of 278 learners graduated from internships and learnerships that were implemented in human resources, finance, broadcast engineering, film and television production, journalism, radio production, and television operations. A 56\% absorption or employment rate for learners was achieved through this intervention.

$\mathrm{R} 2.5 \mathrm{~m}$ was invested in bursaries for employees, children of employees and deserving citizens. Bursaries were sponsored for 231 recipients for scarce and critical skills within the industry and in the country.

According to the $2005 \mathrm{SABC}$ annual report, the committee met five times, on predetermined dates, during the 2004/05 financial year. Special meetings were convened when necessary. In discharging its duties, the committee assessed, reviewed and audited human resources functions, including matters relating primarily to staff training and development, employment equity, and employee relations. Radio sales also started personalised training and development programmes for all the staff, in order to improve performance. [4]

According to the 2010 SABC annual report, training and development skills development continued to be a key focus area for the SABC in the 2009/10 fiscal year. A total of 3198 employees were trained in various areas, focusing on scarce and critical skills such as technical and operational training. A total of 141 employees were awarded bursaries by the SABC. Skills development initiatives have been taken to address scarce and critical skills shortages in the industry. These included the TV broadcast management system (102 employees trained); health and safety training (145 employees trained); and technology internships (93 learners were recruited) [4].

The 2015 SABC annual report stated that, as part of the on-going initiative to develop management and leadership capacity, three in-house leadership development programmes were impemented across the oranisation. These were the people management programme; management development programme; and leadership development

programme. A total of 444 staff members attended training within this portfolio during the financial year. Other SABC training interventions include the Women Empowerment Programme (WEP); coaching and mentoring training; strategic thinking; and various leadership and management courses. [4]

The corporation attributed its R395m loss for the 2015 financial year to the country's poor economic performance and television licence defaulters. In 2014 the organisation reported a $\mathrm{R} 358 \mathrm{~m}$ profit. Revenue rose $4 \%$ to $\mathrm{R} 7.5 \mathrm{bn}$ in this period. The organisation tried to downplay the implication of its poor performance by explaining that profitability was not necessarily its mandate. They further maintained that its focus was sustainability and that the financial results were simply a scoreboard. SABC CEO, Frans Matlala's ultimate message was that the SABC had a sustainable future and that it would carry on fulfilling its mandate [9].

\section{RESEARCH METHODOLOGY}

This research paper follows a quantitative research approach. Quantitative research attempts to understand the facts of research investigation from an outsiders' perspective. It also attempts to keep the research process as stable as possible and controls the investigation and structure of the research situation in order to identify and isolate variables [10].

Forty (40) lower level and middle level managers of SABC were selected for empirical analysis. This sample represented employees of different departments such as IT, the radio sales, news, fm, content hub; religion, finance, and other departments. The convenience sampling technique was selected for the purpose of this study. Convenience sampling is a non-probability sampling procedure where samples are obtained from individuals who are willing and able to respond to the study [11].

Two (2) finance managers were interviewed and assisted the researchers by furnishing the financial reports of the organisation.

Based on the information from the financial reports, other research articles, and other secondary data sources, this study aims to analyse the impact of training and development on the SABC's performance. The study opts for two approaches.

Firstly it relies on the questionnaire, which is divided in three sections. The questionnaire aims to analyse employees' perception of the impact of training and development on individual, team and organisational learning. The second approach aims to analyse the organisation's financial reports and identify its return on assets, current ratio, return on equity and profit margin.

The study aims to analyse similarity or dissimilarity in employees' perception of the organisation's performance.

The questionnaire is based on a five-point Likert scale. This scale is used to measure employee perception of the effectiveness of training and development activities at the SABC. The reliability coefficient (Cronbach's alpha) for the complete segment is .923 , which showcases the reliability of the study.

The following hypothesis is constructed for the study:

Hypothesis 1: Employee training and development significantly impact on organisational performance.

Flowing from the main hypothesis, the following sub-hypotheses are formulated:

Hypothesis 1a: Employee training and development significantly impact on individual learning.

Hypothesis 1b: Employee training and development significantly impact on group learning.

Hypothesis 1c: Employee training and development significantly impact on organisational learning. 


\section{STUdY FINDINGS}

The experience of respondents who completed the questionnaires ranged between 0-5 years (30\%); 6-10 years (40\%); and 10+ years (30\%). Respondents' experience was gathered to ensure that the study covers inputs from both less-experienced and highly experienced teachers and experts of the performance appraisal process.

As mentioned under research methodology, the respondents represented different roles and served in different departments like IT, radio sales, curent affairs, fm, finance, tv sales, sabc education, program sponsorship, logistics service, airtime management, content: children, content: religion, etc.

The majority of the respondents were degree and diploma holders. Their respective fields of study reflected varied educational backgrounds, including an honours in dramatic arts; a post graduate in graphic design; a diploma in finance; an honours in economics; a diploma in marketing and media studies; a national diploma in public management and administration; a BA in communication; an higher diploma in marketing; a masters in media studies; an honours in drama; a law degree; and a BPTC.

Descriptive statistics was used to determine whether the SABC's organisational performance aligns with respondents' answers to the questions.

From the Table I, the Cronbach's alpha test result ranged from 0.77 to 0.93 showing an acceptable degree of reliability of test instruments.

In order to investigate the impact of learning oriented training on organisational performance, this study was subdivided in three sections.

TABLE I: CRONBACH ALPHA

\begin{tabular}{|l|c|c|}
\hline Construct & $\begin{array}{l}\text { Cronbach } \\
\text { Alpha } \alpha\end{array}$ & $\begin{array}{l}\text { No. of } \\
\text { Items }\end{array}$ \\
\hline $\begin{array}{l}\text { Impact of learning-oriented training on } \\
\text { employees' individual learning. }\end{array}$ & 0.983 & 7 \\
\hline $\begin{array}{l}\text { Impact of learning-oriented training on } \\
\text { employees' group learning. }\end{array}$ & 0.973 & 8 \\
\hline $\begin{array}{l}\text { Impact of learning-oriented training on } \\
\text { employees' organisational learning. }\end{array}$ & 0.867 & 7 \\
\hline
\end{tabular}

\section{Section 1: Individual Learning}

This section applied the following critical factors to determine the impact of learning oriented training on employees' individual learning:

\begin{tabular}{|c|c|c|c|c|c|c|}
\hline $\mathbf{X}$ & $\mathbf{f}^{\prime}$ & $\mathbf{F}$ & $\begin{array}{c}\mathbf{d}= \\
(\mathbf{X}-\mathbf{X})\end{array}$ & $\mathbf{d}^{\mathbf{2}}$ & $\mathbf{f}^{*} \mathbf{d}^{\mathbf{2}}$ & $\mathbf{f}^{*} \mathbf{X}$ \\
\hline $\mathbf{5}$ & 7,57 & 8 & 2 & 4 & 32 & 40 \\
\hline $\mathbf{4}$ & 15,43 & 15 & 1 & 1 & 15 & 60 \\
\hline $\mathbf{3}$ & 10,00 & 10 & 0 & 0 & 0 & 30 \\
\hline $\mathbf{2}$ & 4,86 & 5 & -1 & 1 & 5 & 10 \\
\hline $\mathbf{1}$ & 2,14 & 2 & -2 & 4 & 8 & 2 \\
\hline Total & & $\mathbf{4 0}$ & $\mathbf{0}$ & $\sum \mathbf{d}^{2}=\mathbf{1 0}$ & $\mathbf{6 0}$ & $\mathbf{1 4 2}$ \\
\hline & & & & & $\begin{array}{l}\sum \mathrm{f}^{*} \mathrm{~d}^{2}= \\
60\end{array}$ & $\begin{array}{l}\sum \mathrm{f}^{*} \mathrm{X}= \\
142\end{array}$ \\
\hline
\end{tabular}

1. Individuals are able to break out of their traditional mind-sets to see things in new and different ways

2. Individuals feel a sense of pride in their work

3. Individuals have a clear sense of direction in their work

4. Individuals generate various new insights

5. Individuals are aware of critical issues that affect their work

6. Individuals feel confident about their work

7. Individuals feel a sense of accomplishment in what they do

In order to understand and study the overall effect of learning oriented training on employees, the researcher decided to use the $\mathrm{z}$ test for a non-directional, or two-tailed test, where the alternative hypothesis is stated as not equal to $(\neq)$ the null hypothesis.

To analyse the data further, and to conclude the findings, the Z-test was used as a statistical tool in the study. As suggested by [12] the level of significance was $5 \%$, which is a commonly used level and of significance for the researchers. The $\mathrm{Z}$ Test is conducted to measure the significant impact of learning based training on the individual learning of employees.

$$
\begin{gathered}
\sigma x=\sqrt{ } \sum d^{2} /(n-1), \text { Where } d^{2}=(X-X)^{2} \\
\sigma x=0,26 \\
\mu=\sum f^{*} X / n=3,55 \\
Z=(X-\mu) / \sigma_{x}=-2,115 \\
p \text { value }=0.0344
\end{gathered}
$$

The two-tailed $\mathrm{P}$ value equals 0.0344 . By conventional criteria, this difference is considered to be statistically significant. Table I confirms that learning based training programmes have a significant impact on the individual learning of SABC employees. Hence the alternate hypothesis H1a is established.

\section{Section 2: Group Learning}

This section covered the following critical factors to determine the impact of learning oriented training on employees' group learning.

1. We have effective conflict resolution when working in groups.

2. Different points of view are encouraged in group work.

3. Different points of view are encouraged in group work.

4. Groups have the right people involved in addressing the issues.

5. We share our success within the group.

6. In meetings, we seek to understand everyone's point of view.

7. Groups in the organisation are adaptable.

8. Groups are prepared to rethink decisions when presented with new information.

$$
\begin{gathered}
\sigma_{x}=\sqrt{ } \sum d^{2} /(n-1), \text { Where } d^{2}=(X-X)^{2} \\
\sigma x=0,26 \\
\mu=\sum f^{*} X / n=3,62 \\
Z=(X-\mu) / \sigma_{x}=-2,38 \\
P \text { value }=0.0173
\end{gathered}
$$

Table III reflects the organisation's responsibility to impart group-based learning to its employees. The $p$ value $=0.0173$ confirms a significant impact of learning based training on the 
group learning of SABC employees. Hence the alternate hypothesis $\mathrm{H} 1 \mathrm{~b}$ is established.

TABLE III: Z TEST

\begin{tabular}{|c|c|c|c|c|c|c|}
\hline $\mathbf{X}$ & $\mathbf{f}^{\prime}$ & $\mathbf{F}$ & $\begin{array}{c}\mathbf{d}= \\
(\mathbf{X}-\mathbf{X})\end{array}$ & $\mathbf{d}^{\mathbf{2}}$ & $\mathbf{f}^{*} \mathbf{d}^{\mathbf{2}}$ & $\mathbf{f}^{*} \mathbf{X}$ \\
\hline $\mathbf{5}$ & 9,00 & 9 & 2 & 4 & 36 & 45 \\
\hline $\mathbf{4}$ & 12,71 & 13 & 1 & 1 & 13 & 52 \\
\hline $\mathbf{3}$ & 10,00 & 10 & 0 & 0 & 0 & 30 \\
\hline $\mathbf{2}$ & 6,14 & 6 & -1 & 1 & 6 & 12 \\
\hline $\mathbf{1}$ & 2,00 & 2 & -2 & 4 & 8 & 2 \\
\hline Total & & $\mathbf{4 0}$ & $\mathbf{0}$ & $\sum \mathbf{d}^{\mathbf{2}}=\mathbf{1 0}$ & $\mathbf{6 3}$ & $\mathbf{1 4 1}$ \\
\hline & & & & & $\sum^{*} \mathrm{~d}^{2}=63$ & $\Sigma^{*} \mathrm{X}=141$ \\
\hline
\end{tabular}

Section 3. Organisational Learning This Section Covered the Following Critical Factors to Determine the Impact of Learning Oriented Training on Employees' Organisational Learning

1. We have a strategy that positions us well for the future.

2. We have the necessary systems to implement our strategy.

3. The organisation's culture could be characterised as innovative.

4. The organisational structure allows us to work effectively.

5. We have a realistic yet challenging vision for the organisation.

6. We have an organisational culture characterised by a high degree of trust.

7. Our operational procedures allow us to work efficiently.

\begin{tabular}{|c|c|c|c|c|c|c|}
\hline \multicolumn{10}{|c|}{ TABLE IV: Z-TEST } \\
\hline & $\mathbf{f}^{\prime}$ & $\mathbf{F}$ & $\begin{array}{r}\mathbf{d}= \\
(\mathbf{X}-\mathbf{X})\end{array}$ & $\mathbf{d}^{\mathbf{2}}$ & $\mathbf{f}^{*} \mathbf{d}^{\mathbf{2}}$ & $\mathbf{f}^{*} \mathbf{X}$ \\
\hline $\mathbf{5}$ & 1,57 & 2 & 2 & 4 & 8 & 10 \\
\hline $\mathbf{4}$ & 8,29 & 9 & 1 & 1 & 9 & 36 \\
\hline $\mathbf{3}$ & 14,29 & 14 & 0 & 0 & 0 & 42 \\
\hline $\mathbf{2}$ & 9,43 & 9 & -1 & 1 & 9 & 18 \\
\hline $\mathbf{1}$ & 6,43 & 6 & -2 & 4 & 24 & 6 \\
\hline Total & & $\mathbf{4 0}$ & $\mathbf{0}$ & $\sum \mathbf{d}^{2}=\mathbf{1 0}$ & $\mathbf{5 0}$ & $\mathbf{1 1 2}$ \\
\hline
\end{tabular}

$$
\begin{gathered}
\sigma_{x}=\sqrt{ } \sum d^{2} /(n-1), \text { Where } d^{2}=(X-X)^{2} \\
\sigma x=0,26 \\
\mu=\sum f^{*} X / n=2,87 \\
Z=(X-\mu) / \sigma_{x}=0,50
\end{gathered}
$$

Table IV confirms that a learning based training programme does not significantly impact on the organisational learning of SABC employees. Hence the null hypothesis is established. This confirms that employees' perception regarding the impact of training practices on organisational performance is negative. However, it must also be noted that the results reflect a positive impact of training practices on individual learning and group learning.

\section{ANNUAL REPORT: 2013, 2014 AND 2015}

In analysing the SABC's organisational performance, key financial ratios were extracted for the period 2011 to 2015 from the published annual financial statements. These financial metrics and their associated trends were analysed over five years to determine an improvement or deterioration in the organisation's performance. The current ratio was extracted to determine the organisation's ability to pay off its short-term liabilities with its current assets.

A distinct improvement in this ratio over the period is evident from Table 4.6. This confirms the SABC's improved liquidity and efficiency. Secondly the return on assets indicator is utilised in this study to determine the SABC's efficiency in using its assets to generate earnings. The table reflects a somewhat stable level of assets, which can be expected from the SABC's operating history and scale. However, the net income (profit) varied more significantly. While a strong growth in net income for the periods 2011 to 2014 is reflected in Table V, this trend turned sharply lower in the 2015 financial year, dropping to a material net loss. Accordingly, this signifies a reversal in return on assets. However, this would need to be closely monitored in future years to determine if the longer trend remains intact with one-year anomaly, or whether this is indicative of a sustained lower trajectory in profitability. As a result of the organisation's net loss in 2015, the profit margin analysis was also impacted. For the period 2011 to 2014, the SABC produced healthy profit margins, which increased over the period. However, as shown previously, the result of the net loss in 2015 is that all profit margins are eradicated for that period "submitted for publication" [5].

TABLE V: DESCRIPTIVE STATISTICS

\begin{tabular}{|l|l|l|l|l|l|l|l|}
\hline & Mean & Med & Max & Min & $\begin{array}{l}\text { Std. } \\
\text { Dev. }\end{array}$ & skew & Kurt \\
\hline $\begin{array}{l}\text { Current } \\
\text { Ratio }\end{array}$ & 1,838 & 1,940 & 2,01 & 1,63 & 0.19 & $-0,533$ & $-3,23$ \\
\hline $\begin{array}{l}\text { Return } \\
\text { on } \\
\text { Assets }\end{array}$ & 0,025 & 0,068 & 0,074 & $-0,11$ & 0,08 & $-1,948$ & 3,79 \\
\hline $\begin{array}{l}\text { Profit } \\
\text { Margin }\end{array}$ & 0,021 & 0,049 & 0,559 & 0,022 & 0,05 & $-1,929$ & 3,70 \\
\hline
\end{tabular}

It is evident from Table $\mathrm{V}$ that the mean current ratio is 1.838. This is a comfortable financial position for most enterprises. However, acceptable current ratios vary from industry to industry. The median current ratio is calculated as 1.94. The mean value of return on assests is reflected as 0.025 and the median is calculated as 0.068 . The mean profit margin is 0,021 and the median profit margin is 0.049 .

As the net income turned negative in 2015, this single year data point has an impact on the mean values for the return on assets and profit margin calculations. As it is too early to determine if this is a once off drop, or a sustainable trend lower, utilizing the median values is suggested as a more accurate representation of the period analyzed. If this is utilized, both return on assets and profit margin are acceptable levels for an organisation such as the SABC.

While other measures of skewness (based on quartiles or on the methods of moments) are also used sometimes, we would, in respect of the measures of skewness and kurtosis, use the first measure of skewness based on mean and mode or on mean and median. Kurtosis is also used to measure the peakedness of the curve of the frequency distribution [13]. 


\section{DisCUSSION OF THE FINDINGS OF THE STUDY}

As highlighted by [7], it is important to note that training professionals need to improve their awareness of and involvement in integrating training in various business strategies if they were to increase strategic visibility, importance, and credibility in their organisations. The current study confirms that top management and executives need to genuinely realise the strategic importance of the training function and training professionals as a value-added source for sustained competitive advantage. This can be achieved by increasing the level of training professionals' involvement in the organisation's strategies and implementing a structure that clearly aligns training activities with corporate objectives and goals. The study confirms that training impacts on individual and group learning but does not significantly impact on the SABC's organisational performance. Research confirmed stability in the SABC's performance. This was measured by analysing the current ratio, profit margin and return on assets, which are all facing a setback because of losses incurred in year 2015 .

\section{LIMITATIONS OF THE STUDY}

The study focused on a small sample of 40 middle level managers. The results of this study can therefore not be generalised to a broader population as the study was conducted with only small number of managerial level respondents. It is therefore not representative of the whole geographical area of South Africa. As such it might not have provided a true reflection of the perception of the impact of training and development on the SABC's organisational performance. Since the policy and practice of training and development is developed at top management level, it would have been ideal if a number of senior level employees or managers from different departments could have been included to obtain a clearer picture of the impact of training and development on organisational performance.

Furthermore, only managers participated in the study. Further and more inclusive research with other stakeholders and a greater number of employees from all levels of the organisation may produce a richer source of information.

\section{SUGGESTIONS FOR FURTHER RESEARCH}

Emphasis should be given on correlating the training and development practice of the SABC with the organisation's compensation management. Further research should be conducted to identify the correlation of training and development with the organisation's performance management system. Research from organisations in different industries would be useful in refining and validating the data. It would also be interesting to monitor the future performance of the case study in order to determine whether technological based training interventions generate employee job satisfaction in the organisation.

\section{CONCLUSION}

The South African Broadcasting Corporation must follow a step-by-step approach towards improving professionalism. They need to evaluate their existing skill base to identify gaps, formulate training programmes and plans, and to develop training need design based on the demands of job descriptions. This study also shows that organisations' financial performances depend on several factors, some of which include commitment of workers to the organisation and employee competence.

Thus, for improved financial performance, organisations must engage in training and development initiatives on a regular and consistent basis, all of which should be focused on making employees more effective and efficient in performing their duties. This study further confirms the importance of conducting a systematic process to determine employee training needs of employees on a continuous basis and to effectively fill identified KSA gaps for attaining the organisational goal of improving financial performance.

The current study contributes to a greater understanding of the strategic integration of training and its impact on the organisation's competitiveness. This paper, using the resource-based view of the organisation as theoretical background determines whether the integration of training in the organisation's business strategies increases the impact of training on the organisation's performance.

In summary, the SABC exhibited increased financial health during the period 2011 to 2015 , with improved efficiencies and asset utilisation. However the net loss in 2015, although against trend, significantly impacted on profitability in the financial year, and will require close monitoring in future reporting periods.

Executives and top management teams need to integrate training and involve training professionals in every business strategy.

\section{REFERENCES}

[1] C. O. Chidi and O. P. Okpala, Theoretical and Methodological Approaches to Social Sciences and Knowledge Management, pp. 279-292, 2012.

[2] V. F. Peretomode and O. Peretomode, Human Resources Management: Principles, Policies and Practice, Lagos: Onosomegbowho Ogbinaka Publishers, 2001.

[3] G. Maritz, "The most critical issues facing managers in South Africa," Acta Commercii, vol. 2, pp. 1-10, 2002.

[4] SABC. [Online].

[5] R. Noe, J. Hollenbeck, B. Gerhart, and P. Wright, Human Resource Management: Gaining a Competitive Advantage, 4th ed., Boston: McGraw Hill, p. 38, 2003.

[6] F. D. Kum, R. Cowden, and A. M. Karodia, 2014, "The impact of training and development on employee performance: A case study of Escon consulting," Singaporean Journal of Business Economics, and Management Studies, pp. 72-105.

[7] S. Katcher and T. Snyder, Organisational Commitment, USA: Atomic Dog, p. 90, 2003.

[8] T. Frost, S. Vos, and J. Dreyer, 2000, Organisational Development Mumbai: Jaico Publishing.

[9] BDLIVE. (August 5, 2016). [Online]. Available: http://www.bdlive.co.za/national/media/2015/09/23/sabc-turns-r358 m-profit-into-almost-r400m-loss-as-advertisers-walk

[10] C. Welman, F. Kruger, and B. Mitchell, Research Methodology, 3rd ed. Oxford University Press, Cape Town, 2005.

[11] Russell and Purcell, Online Research Essentials: Designing and Implementing Research Studies, San Francisco: Jossey-Bass, 2009.

[12] K. G. Kanji, 2006, 100 Statistical Tests, London: Sage Publications.

[13] C. R. Kothari, Research Methodology, New Age Publishers, Jaipur, p. 131,2004 


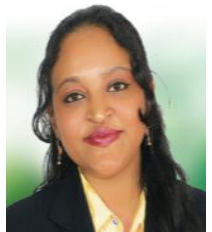

Abhinanda Gautam is the academic head of Regenesys Business School, Johannesburg. She is a dedicated, resourceful and innovative educationist with academic experience of over $14^{+}\left(11^{+}\right.$years in teaching and $3^{+}$years in functional areas: HR and marketing across the industry), motivating and directing students while maintaining, high interest and achievement. Possess a positive and effective teaching style with the willingness to work above and beyond the call of duty, currently she is spearheading functions as the academic head of MBA, Regenesys Business School, Johannesburg.

She keeps abreast of developments in the field, liaising with colleagues, and participating in professional conferences. She is an exceptional communicator with students and parents, demonstrating a caring and empathetic attitude, promoting the welfare of the institution by enhancing self and organizations' efficiency and productivity.

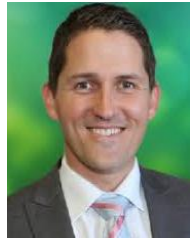

Devin Shutte is the CEO of My Wealth investments. Devin is an experienced financial market participant, with more than 10 years experience as a professional portfolio manager and trader. Devin is a registered JSE Equity Trader, and holds a B.Comm Honours in Financial Analysis and Portfolio Management. As a previous managing director of an Investment Management House, he has combined his experience, financial nous and emotional intelligence to successfully navigate the high seas of the financial markets. His pragmatic and independent approach to investing has borne much success to date. He is passionate about the markets, and about encouraging and teaching others to invest and grow. Devin is also a regular commentator for financial media. 